\title{
TRANSPANTHERS: THE GREYING OF TRANSGENDER AND THE LAW
}

\author{
TARYNN M WITTEN AND STEPHEN WHITTLE"
}

[Aging is a universal normalising process. No gender identity, no body form, no sex/sexuality is necessarily fixed in time and none of these facets of the human spirit are invulnerable to the ongoing processes of aging. Aging unites us in a way that no other process can. It is universal and inevitable. The emergence of a vocal population of transgender individuals of all ages mandates that we address the problems of aging in this population. The combined stigma of being elderly and transgender can serve as a strong traumatising force in the lives of such individuals. In this article, we focus on the interaction of aging, non-normative body forms and identities, and the law.]

\footnotetext{
"Senior Fellow and Executive Director, TranScience Research Institute, United States.

*** Reader in Law, School of Law, Manchester Metropolitan University, United Kingdom.
} 


\section{INTRODUCTION AND BACKGROUND}

Aging is a universal normalising process. No gender identity, no body form, no sex/sexuality is necessarily fixed in time and none of these facets of the human spirit are invulnerable to the ongoing processes of aging. Aging unites us in a way that no other process can. It is universal and inevitable. ${ }^{1}$

Gender reassignment surgeries were first performed in the 1930s, becoming features of the public consciousness in the early 1950s with Christine Jorgenson's return from Denmark to the USA. ${ }^{2}$ Today, hormonal and surgical reassignments are regularly sought. Two US gender realignment surgeons have stated that they are performing an average of two surgeries/day, 4-5 days/week, 48 weeks/year and that they have a waiting list of over two years. In recent years, developments have also occurred in 'trans' terminology that shift the emphasis away from 'transsexual' identities that appear to make a clear change from one sex to the other, to 'transgender' identities which recognise a wide diversity of gender expression and gendered bodies. ${ }^{3}$ Consequently, for the first time in this modern historical period, we are faced with an aging 'trans' community with a wide range of health and social care needs conjoint with their diverse sexed and gendered bodies and identity. Moreover, this community contains many cohorts of individuals, each with their own more specialised needs and who, as they age, will need various degrees of specialised attention beyond that of the "normative" aging processes. ${ }^{4}$

In this article 'trans' will be used to refer to the inclusive community of transgender and transsexual people. 'Transgender' represents those people who live a significant part of their lives in their new gender role and who may or may not use hormonal interventions to change their body form. Hence, this population includes crossdressers (men and women who take on the appearance of the other gender, usually on a social or part-time basis) and transgender people (whose psychological selfidentification is as the other sex and who alter their behaviour and/or appearance to conform to this internal perception). This definition also allows us to include those individuals who would be termed transvestites as well as those individuals who fall outside of the traditional Western dichotomous gender definition (Native American Dual Spirits, Tewa Indians, etc). Additionally, it allows us to include cultural variation in terms used to describe members of the transgender population. 'Trans-

\footnotetext{
${ }^{1}$ Tarynn M Witten, 'Aging and Gender Diversity' (2003a) 4(4) Social Work Today 28.

${ }^{2}$ Stephen Whittle, Respect and Equality: Transsexual and Transgender Rights (2002)

${ }^{3}$ Dallas Denny 'The Paradigm Shift is Here' (1995) 4:1 Aegis News; Stephen Whittle, The Transgender

Debate: The Crisis Surrounding Gender Identities (2000).

${ }^{4}$ Witten, 'Geriatric Care and Management Issues For The Transgender And Intersex Populations' (2002) 12(3) Geriatric Care and Management Journal 20, Tarynn M Witten and A.Evan Eyler, 'Healthcare Issues: Transsexuals, Transgenders, and Cross-Dressers' (2004a) 11(1) Healthcare and Aging 4

5 Tarynn M Witten, Esben Benestad, Richard Ekins, Randi Ettner, Katsuki Harima, Dave King, Mikael Landén, Nuno Nodin, Volodymyr P'yatokha \& Andrew Sharpe, 'Transgender and Transsexuality' in
} 
sexual' will be used for those people who proceed to some gender reassignment surgery which may or may not be inclusive of genital reconstructive surgery. ${ }^{6}$ Lastly, it is important to understand that the terminology used in this discussion is temporally dynamic and culturally varying. ${ }^{7}$

\section{TRANSGENDER LIVES}

Trans life experiences are not always easy. Social stigma is still a major feature of trans lives in areas of employment, personal relationships, health care and personal safety. Trans lives are as complex and varied as one might imagine. Witten and Eyler have demonstrated that mid-to-late life issues of the transgender population are richly complex, full of courage, coping, risk and resilience, and that they are grounded in a socio-ecological landscape of systemic actual and perceived violence and abuse. ${ }^{8}$

They further report that in a sample of 174 individuals (sample biased towards Caucasian, middle to upper-class individuals, and having age range 22-79 years) there was a high degree of violence and abuse suffered. ${ }^{9}$ Sadly, much abuse and violence is suffered prior to the age of eighteen years old. Of the 86 respondents to the childhood violence question of the TLARS ${ }^{10}$ study, 60 of them stated that they had suffered some sort of violence or abuse (multiple choices could be checked) prior to age 18. Individuals who responded as having suffered some sort of violence were asked a series of clarifying items that addressed whether or not the respondents believed that any of these acts of violence constituted 'hate crimes' (i.e., that the acts occurred because of hatred of the respondent's race, gender, sexual orientation, or gender presentation, multiple responses were allowed). Of $n=143$ responses, $\mathrm{n}=101(70 \%)$ stated Yes, $\mathrm{n}=23(16 \%)$ indicated No, and $\mathrm{n}=19(13 \%)$ chose Not Applicable. At this time, correlations between type of violence and perception as a hate crime are not available. Results of the WTNAS (Washington Transgender Needs Assessment Survey ${ }^{11}$ ) are equally disturbing. ${ }^{12}$ The WTNAS study reports $26 \%$ harassment, $18 \%$ intimidation, $17 \%$ assault with a weapon, $14 \%$ sexual assault/rape and minor percentages in other areas such as police entrapment, police sweep, blackmail/extortion, and unjustified arrest. Of the $n=89$ TLARS respondents who indicated that they had experienced an act of social mistreatment,

Carol R Ember and Melvin Ember (eds), The Encyclopaedia of Sex and Gender: Men and Women in the World's Cultures (2003).

${ }_{6}^{6}$ Tarynn Witten and A Evan Eyler, 'Hate Crimes and Violence Against the Transgendered' (1999) 11 Peace Review 461.

${ }^{7}$ Witten and Eyler, above n 4.

${ }^{8}$ Tarynn Witten and A Evan Eyler, 'Hormones and Oral Health: Implications for the Transgender

Population, (2004b) in preparation.

9 Witten and Eyler, above $\mathrm{n} 6$.

${ }^{10} \mathrm{See}<\mathrm{http}: / /$ www.transcience.org $>$

${ }^{11}$ Jessica Xavier and Ron Simmons, Final Report of The Washington Transgender Needs Assessment

Survey (2000): Available on-line at 〈http://www.gender.org/resources/dge/gea01011.pdf〉

${ }^{12}$ Personal communication from Jessica Xavier. 
abuse or violence, $n=62(70 \%)$ indicated that they had suffered some form of street harassment of verbal abuse at some time in their lives and $n=16(18 \%)$ had suffered an act of rape or attempted rape. The continuing US legal system's failure ${ }^{13}$ to respond to violence and abuse against the trans community, and the failure to record such crimes by their distinctive victim group in many states contributes to a sense that transphobic crimes are invisible, thereby silently sanctioning the aforementioned violence. Sharpe \& Moran $^{14}$ report a general acceptance of violence against trans-people and a failure to report to Criminal Justice Authorities in Australia. Anecdotal reports to the TLARS from other countries confirm violence and murder perpetrated against trans-identified persons in Iran, Iraq, and numerous Central and South American countries. ${ }^{15}$ More recent reports further corroborate these facts. ${ }^{16}$

Results from the work of Witten \& Eyler have demonstrated the profound public health hazard associated with the violence and stigma against the transgender community. ${ }^{17}$ However, their research supports the argument that the stigma extends into other areas as well. In particular, it has profound impact on the financial and medical well-being of this population. While the sample population from the longitudinal study was reasonably well off financially, it was only through this success that they were able to pay for the necessary drugs and other medical interventions necessary to both begin and subsequently maintain the transition. Results from the Washington Transgender Needs Assessment Study (2000) document significantly lower educational levels, $42 \%$ unemployment, and significantly lower incomeearning levels $(48 \%$ of the WTNAS respondents state that they could not afford care, $29.6 \%$ state that they have either no insurance or insurance that does not cover the transgender healthcare related needs). Additionally, in the WTNAS study, 37\% of those employed worked as service industry workers, $14.5 \%$ as private sector office workers, $5.5 \%$ as sex industry workers, and the rest in other categories, with only $9 \%$ working as private sector professionals). Clearly, the type of employment status will have significant impact on the mid-to-later life issues of the transgender population.

This is not a uniquely North American experience for trans people. In the United Kingdom, despite employment protection since 1994, results from a survey in 2003 indicated a very poor experience of transition in the workplace for trans people with many suffering harassment and violence. Many of their employers were still not providing them with access to toilet facilities appropriate to their new gender roles. However, the great majority of respondents did not feel that, aside from any difficulties created for them by other people at work, their transition had, at the time or currently, made them less able to do their jobs. Yet many transsexual employees who had recently commenced transition had been forced to leave their jobs either

\footnotetext{
${ }^{13}$ See <http://www.ngltf.org/library/index.cfm > for current Civil Rights and Hate Crimes maps

${ }^{14}$ Andrew Sharpe and Lesley Moran, 'Reporting Transgender Violence: Encounters with the Police,

(2000) 39 Polare: Available at <http://www.gendercentre.org.au/39article2.htm>

${ }_{15}$ Witten and Eyler, above n 6.

${ }^{16}$ Emilia Lombardi, Rikki A Wilchins, Dana Priesing and Diana Malouf, 'Gender Violence: Transgender Experiences with Violence and Discrimination' (2001) 42(1) Journal of Homosexuality 89.

${ }_{17}$ Witten and Eyler, above n 6.
} 
by their employers or because of the resultant conditions at work. The survey also evidenced high unemployment rates, and a move from employment into 'long term' incapacity and social welfare benefits. ${ }^{18}$

\section{Abuse, Violence and the Aging Process}

The impact of this type of trans-related violence, abuse and long term poverty can be measured across the life cycle in that early and mid-life violence and abuse have been shown to have direct impact on health, well-being, and quality of life in the mid-to-later life years. ${ }^{19}$

Stallings et al elaborate a theory of well-being involving life-events and psychological well-being. ${ }^{20}$ For example, Bengtsson \& Lindstrom demonstrate that historically childhood misery can have significant effects on mortality in old age. ${ }^{21}$ Dressler and Bindon examine the effects of social status, social context, on arterial blood pressure, finding a direct link between blood pressure and the other two variables. $^{22}$ Kraaij, Arensman, \& Spinhoven demonstrate a profound relationship between negative life events and depression in elderly persons. ${ }^{23}$ Kubzansky, Berkman, \& Seeman illustrate a significant relationship between social conditions and stress in elderly persons. ${ }^{24}$ Pinquart \& Sorenson demonstrate that there is a significant relationship between socio-economic status, social network, and competence on subjective well-being in later life, ${ }^{25}$ while Rautio, Heikkinen \& Heikkinen further strengthen the understanding by demonstrating a significant relationship between socio-economic factors and physical and mental capacity in elderly men and women. ${ }^{26}$ Turrell et al demonstrate the effects of socioeconomic position across

\footnotetext{
${ }^{18}$ Stephen Whittle, 'Employment Discrimination and Transsexual People' (2003) Available on-line at <http://www.gires.org.uk>.

${ }^{19}$ Neil Krause and Benjamin Shaw, 'Role-Specific Feelings of Control and Mortality' (2000) 15(4) Psychology and Aging 617.

${ }^{20}$ Michael Stallings, Charlotte C Dunham, Margy Gatz, Laura Baker and Vem L. Bengston, 'Relationships among Life Events and Psychological Well-Being: More Evidence for a Two-Factor Theory of Well-Being' (1997) 16(1) Journal of Applied Gerentology 104-119

${ }^{21}$ Tommy Bengtsson and Martin Lindstrom, ' Childhood Misery and Disease in Later Life: The Effects on Mortality in Old Age of Hazards Experienced in Early Life, Southern Sweden, 1760-1894' (2000) 54(3) Popular Studies 263.

22 William E Dressler and James R Bindon, 'Social Status, Social Context, and Arterial Blood Pressure' (1997) 102(1) American Journal of Physical Anthropology 55-66.

${ }^{23}$ Vivian Kraaij, Ella Arensman and Philip Spinhoven, 'Negative Life Events and Depression in Elderly Persons: A Meta-Analysis' (2002) 57B(1) Journal of Gerontology: Psychological Sciences 87-94.

${ }^{24}$ Laura Kubzansky, Lisa F Berkman and Teresa Seeman, 'Social Conditions and Distress in Elderly Persons: Findings from the Macarthur Studies of Successful Aging' (2000) 55B(4) Journal of Gerontology 238.

${ }^{25}$ Martin Pinquart and Sylvia Sorenson, 'Influences of Socio-Economic Status, Social Network, and Competence On Subjective Well-Being in Later Life: A Meta-Analysis' (2000) 14(2) Psychology and Aging 187.

${ }^{26}$ Nina Rautio, Eino Heikkinen and Riitta-Liisa Heikkinen, 'The Association of Socio-Economic Factors With Physical and Mental Capacity In Elderly Men And Women' (2001) 33 Archives of Gerontology and Geriatrics 163.
} 
the life course and its effect on cognitive function in late middle age. ${ }^{27}$ Everard et al address the impact of social support networks on functional health of the elderly. They demonstrate a strong correlation between strong social support networks and successful aging. ${ }^{28}$ Based upon the data presented in the previous sections and the results from the "normative" geriatric and Gerontological research literature, it is not difficult to posit that the transgender population is at a significant disadvantage and risk when it comes to biomedical and psycho-socio-cultural well-being given the degree of difficulties that it faces. ${ }^{29}$

\section{The Greying OF TRANSGENDER: SOME BASIC DEMOGRAPHICS}

An accurate estimate of the transgender population is extremely difficult due to the high degree of stigma and consequent potential for violence and associated lack of legal protection. This problem is more comprehensively addressed by Witten when she analyses issues surrounding the problem of estimating the older-age structure of the transgender and intersex demographic populations. ${ }^{30}$ In Table [1] of that paper, she presents the first published estimates of the 65+ year-old transgender population sizes in the US and world-wide, based upon population estimates from the 1999 World Population Profile. Based upon incidence estimates for transgender identities in the US, Witten estimates a projected 65+ year-old population of 700,000 2.1 million individuals and a world-wide $65+$ year-old population of 4.1 million 12.3 million individuals. Even a reduction of $1 / 10^{\text {th }}$ still leaves us with a significant trans-elderly population having a variety of unique needs. Furthermore, if we include the impact upon family, friends, and significant others, issues of aging in the trans-identified population impact a large number of individuals both in the US and worldwide.

\section{Trans Legal Rights and Recognition}

Since the 1990s there has been some success in changing social attitudes towards trans people. In the last 15 years the trans community has organised ${ }^{31}$ and devel-

\footnotetext{
${ }^{27}$ Gavin Turrell, John W Lynch, George A Kaplan, Susan A Everson, Eeva-Liisa Helkalac, Jussi Kauhanen and Jukka T Salonen, 'Socioeconomic Position Across the Lifecourse and Cognitive Function In Late Middle Age' (2002) 57B(1) Journal of Gerontology Series B: Psychological Sciences and Social Sciences 43-S51.

${ }^{28}$ Kelly M Everard, Helen W Lach, Edwin B Fisher and M Carolyn Baum, 'Relationship of Activity and Social Support to the Functional Health of Older Adults' (2000) 55B(4) Journal of Gerontology 208.

${ }^{29}$ For a more exhaustive discussion of these issues, see Witten above n 4, 20-24; and Christine F Hartley and Stephen Whittle, 'Different Sexed and Gendered Bodies Demand Different Ways of Thinking About Policy and Practice' (2003) 15(3) Practice: A Journal of the British Association of Social Workers 61.

${ }^{30}$ Tarynn M Witten, 'Aging and Gender Diversity' (2003a) 4(4) Social Work Today 28.

${ }^{31}$ Whittle, above $\mathrm{n} 3$.
} 
oped complex personal and political identities. ${ }^{32}$ Though there have been extreme difficulties in attempting to invoke the legislative process there have been legislative and case law successes throughout the world, particularly in the last 5 years. ${ }^{33}$ Since 1990, a growing number of precedents for express protection have been achieved. The anti-discrimination legislation of a number of cities in the USA includes 'gender identity' as a prohibited ground. ${ }^{34}$ In the US state of Minnesota, anti-discrimination legislation defines 'sexual orientation' as including 'having ... a self-image or identity not traditionally associated with one's biological maleness or femaleness ${ }^{35}$ and in California gender and gender expression are protected categories under the state's Hate Crime's legislation. ${ }^{36}$

All states in Australia now prohibit discrimination on the grounds of sexual orientation. Discrimination against transsexual persons is also expressly prohibited in South Australia ${ }^{37}$ and in the Northern Territory of Australia ${ }^{38}$ where the ground sexuality is defined to include 'transsexuality', and in the Australian Capital Territory, where 'transsexuality' is a separate prohibited ground. ${ }^{39}$ In New South Wales in Australia ${ }^{40}$ discrimination is prohibited 'on transgender grounds' and the legislation refers to people as 'being transgender'. Further, the Australian Family Court (affirmed by the Full Court of the Family Court of Australia) found that a transsexual man is a man for the purposes of marriage so, it could be argued, effectively, recognising a legal change of sex. ${ }^{41}$

In 1989 the Parliamentary Assembly of the Council of Europe adopted Recommendation 1117 on discrimination against transsexuals and a Resolution on the condition of transsexuals, which in cases of transsexualism called on member states to introduce legislation whereby all discrimination in the enjoyment of fundamental rights and freedoms is prohibited in accordance with Article 14 of the European Convention of Human Rights. ${ }^{42}$

In 1994, the European Court of Justice found that it is no longer appropriate to discriminate against a transsexual person. In the proceedings of $P v S$ and Cornwall County Council ${ }^{43}$ Advocate General Tesauro stated:

\footnotetext{
${ }^{32}$ Stephen Whittle, 'The Trans -Cyberian Mailway' (1998) 7(3) Social and Legal Studies 389.

${ }^{33}$ Whittle, above n 2.

34 These cities include Minneapolis, San Francisco, Evanston (Illinois), Louisville (Kentucky) and

Houston.

${ }_{35}^{35}$ Minn. Stat. § 363.01(45) (1993).

${ }^{36}$ Cal. Penal Code $\$ 422.6-422.95$ AB (1999).

${ }^{37}$ Equal Opportunity Act 1984 (WA).

${ }^{38}$ Anti-Discrimination Act 1996 (NT)

${ }^{39}$ Discrimination Act 1991 (ACT).

${ }^{40}$ Anti-Discrimination Act 1977 (NSW), amended by the Transgender (Anti-Discrimination and Other Acts Amendment) Act 1996.

${ }^{41}$ Re Kevin (Validity of Marriage of Transsexual) [2001] Fam CA 1074.

${ }^{42}$ Recommendation 1117 (1989) Parliamentary Assembly of the Council of Europe.

${ }^{43}$ P v S and Cornwall County Council Case C-13/94 [1996] European Court Reports I-2143, I-2165.
} 
To my mind, the law cannot cut itself off from society as it actually is, and must not fail to adjust to it as quickly as possible. Otherwise it risks imposing outdated views and taking on a static role. In so far as the law seeks to regulate relations in society, it must on the contrary keep up with social change, and must therefore be capable of regulating new situations brought to light by social change and advances in science. From that point of view, there is no doubt that for present purposes the principle of the alleged immutability of civil status has been overtaken by events. This is so in so far as and from the time that the fact that one cannot change one's sex for bureaucratic and administrative purposes no longer corresponds to the true situation, if only on account of the scientific advances made in the field of gender reassignment. ${ }^{44}$

adding, when calling upon the European Court of Justice to afford employment protection to transsexual people:

I am well aware that I am asking the Court to make a 'courageous' decision. I am asking it to do so, however, in the profound conviction that what is at stake is a universal fundamental value, indelibly etched in modern legal traditions and in the constitutions of the more advanced countries: the irrelevance of a person's sex with regard to the rules regulating relations in society. ${ }^{45}$

Throughout Europe there is ever-wider recognition of transsexuality both by legislation and judicial decision and gender reassignment surgery is allowed in every member state of the European Community. In 2002, the European Court of Human Rights held that this social change resulted in a right to marry and privacy in the acquired gender role. ${ }^{46}$

As a result, in the United Kingdom, the Gender Recognition Act $2004^{47}$ received Royal Assent in July of 2004. The Act is the UK government's response to the decision of the ECHR in the cases of Goodwin $v U K$ and $I v U K .{ }^{48}$ The Court held that transsexual people had a right to legal recognition, to a new birth certificate to record the gender they now live in, and that the right to marry could no longer be refused.

The Act will come into force in April 2005. It creates Gender Recognition Panels of lawyers and doctors who will award Gender Recognition Certificates to success-

\footnotetext{
${ }^{44}$ Ibid [9].

${ }^{45}$ Ibid [24].

${ }^{46}$ Christine Goodwin v UK Government, application No. $28957 / 95$ (1995) ECHR, Iv UK Government, application No. 25608/94 (1994) ECHR.

${ }^{47}$ Gender Recognition Act 2004 (UK).

${ }^{48}$ Christine Goodwin v UK Government, application No. $28957 / 95$ (1995) ECHR, I v UK Government, application No. 25608/94 (1994) ECHR.
} 
ful applicants who are over 18, who have been medically diagnosed, who can evidence that they have lived in their new gender for at least 2 years and declare that they intend to do so for the remainder of their lives. The Act is not predicated on surgical intervention though it is acknowledged that evidence of some gender reassignment surgery is likely to ease the route to a Gender Recognition Certificate.

Similarly both Japan ${ }^{49}$ and South Africa ${ }^{50}$ have recently afforded legislation for the recognition of the acquired gender of people with "gender dysphoria". Albeit that there may not as yet be an international consensus that 'gender identity' should be treated like sex, race or religion, there is undoubtedly a growing awareness of and a recognisable trend towards acknowledging the extent of the discrimination that trans people face.

However, whenever the list of grounds on which discrimination should be barred is being proposed, although the treatment individuals complain of is inevitably concerned with the contradictory appearance of civil documentation or legal status and the body morphology of the person who has to daily represent themselves, the solution bringing equal treatment, respect and dignity cannot be based in legislation alone. It is only by including, in all jurisprudential areas, the principle that there will be no discrimination based on gender identity that we shall see not just the state but the public and private sectors also being obligated to initiate some steps towards addressing the apparently contradictory bodies in which trans people live their lives. As the European Court of Human Rights held:

No concrete or substantial hardship or detriment to the public interest has indeed been demonstrated as likely to flow from any change to the status of transsexuals [and] society may reasonably be expected to tolerate a certain inconvenience to enable individuals to live in dignity and worth in accordance with the sexual identity chosen by them at great personal cost. ${ }^{51}$

\section{Evaluating Needs}

It is both medically incorrect and ethically wrong to assume that trans people's needs only relate to gender reassignment therapies and surgeries. Health and socioeconomic needs for the trans community are much more complex and involve the lifelong needs, not only of maintaining a 'trans' body and aspired gender role, ${ }^{52}$ but

\footnotetext{
${ }^{49}$ A Law Concerning Special Rules Regarding Sex Status of a Person with Gender Identity Disorder 2003 (Japan) No. 111

${ }^{50}$ The Alteration of Sex Description and Sex Status Act 2003 (South Africa).

${ }^{51}$ Christine Goodwin v UK Government, application No. 28957/95 (1995) ECHR, I v UK Government application No. 25608/94 (1994) ECHR,. [91].

${ }_{52}$ Paula Stephens and Stephen Whittle, A Pilot Study of Provision for Transsexual and Transgender People in The Criminal Justice System, and the Information Needs of their Probation Officers, Report
} 
also the consequences of low income/poverty for many and the ongoing social stigmatisation that still exists worldwide.

The 1990s have also seen a great increase in the number of people choosing to undertake some or all of the gender reassignment therapies available, but this means that many who are now approaching old age will be 'young trans people' in terms of their life management skills. ${ }^{53}$ Hartley and Whittle proposed that:

It is very likely that social welfare services will soon have to make provision for the needs of this emergent community, particularly as those who were previously excluded may well be those who already have significant needs due to age, health, disability or social status. $^{54}$

a fact that is echoed by Witten. ${ }^{55}$ The emergence of a vocal population of trans individuals of all ages mandates that we address the problems of aging in this population. The combined stigma of being elderly and trans can serve as a strong traumatising force in the lives of such individuals, as they face disclosing their 'different' bodies and their care needs in an environment which has never been known to be conducive to respecting difference. Let us begin our discussion with some mini-case examples.

\section{Old, Trans and the Healthcare/Social Care System}

Case 1: UK Linda is a 63 year old male to female trans woman. She had genital recontructive surgery to create a vagina over 20 years ago. After vaginal bleeding she is found to have precancerous cells within the neo-vagina. Her Health Authority is insisting that they do not have any speciality in this area and that she must be referred back to the national Gender Identity Clinic (GIC). Linda is extremely concerned because the GIC has no experience of cancer treatment (it is a psychiatric unit), and it has a waiting list of over 18 months.

In Linda's case there is an assumption that once a transsexual, always a transsexual. In fact Linda has been living in her target gender role for almost 28 years. She has a partner but they are not married because of the legal impediment. Her health is poor because of long term hormonal therapy which was originally poorly pre-

for the Home Office, Manchester Metropolitan University School of Law (2001); Witten, above n 4;

Witten and Eyler, above $\mathrm{n} 4$.

53 Witten and Eyler, above $\mathrm{n} 6$.

${ }^{54}$ Hartley and Whittle, above n 29.

${ }^{55}$ Witten, above $\mathrm{n} 4$. 
scribed. She has faced unemployment from when there was no job protection. She is astonished that now, when she has pre-cancerous cells, that her neo-vagina is not regarded as a woman's and that she is not to be treated as any other woman within the Health Authority (HA) area. This case was to prove extremely difficult to expedite, with the HA arguing that their only obligation was to ensure she received treatment for gender dysphoria and that whatever complications that had arisen came out of the associated treatment. They were effective in arguing that they had no expertise in cancer in the neo-vagina in their region, but the national GIC was extremely helpful in providing evidence that this was not a matter they had any expertise in either. As the neo-vagina had been constructed from part of the colorectal system, this enabled referral under the national cancer treatment guidelines ${ }^{56}$ to a gynaecologist who had also undertaken genital reconstruction in the past. This is a prime example of an important facet of the trans experience; 'everything that goes wrong with you is because of your transgender status and can be blamed on that.' Consider the following case example.

Case 2: UK: James, a trans man of 71 who had undergone chest reconstruction but not genital surgery, was in the stages of early Alzheimer's. He was placed within a local authority care home where every other client was female. The staff at the care home was very uncomfortable with meeting his bodily needs and were very unhappy with his constant removal of his incontinence pads. They had also taken to not passing on his post which included a support group magazine, deciding that he was not able to read and understand it. A local volunteer visitor contacted a support group after discovering James very distressed.

James had had no visitors as he had no family with whom he had kept in touch. Since his transition over 30 years ago he had led a very isolated life. It was arranged for him to meet a local trans man. On chatting with him it was discovered that he was extremely distressed with the paper pants and incontinence pads used. James called them 'sanitary towels' and regarded them as women's aids. After discussion with the home, who were very reluctant to act, the volunteers found a local gay men's residential home which provided nursing care and who would accept James. The local authorities were not willing to transfer him into a private home though. After a threat to invoke the jurisdiction's Disability Discrimination Act, the local authority agreed to the transfer so long as excess nursing costs could be met from elsewhere. The HA agreed to meet the cost of nursing care and combined with a small grant from a Gay charity this enabled him to move. Being in a 'men's' home, James became much happier.

The Western biomedical healthcare system, with few exceptions, pathologises trans-behaviours and intersexed bodies - 'right mind/right body vs. wrong mind/right body or right mind/ambiguous body'. ${ }^{57}$ Unlike the pathologisation of

\footnotetext{
${ }^{56}$ National Institute for Clinical Excellence, Improving Outcomes in Colo-Rectal Cancers (2004).

${ }^{57}$ Joan Cassell, The Surgeon in the Woman's Body (1998).
} 
intersex via medicalisation, "trans" is invisiblised, as well as pathologised, through a classification of mental pathology. ${ }^{58}$ This is further evident from the denial of healthcare coverage. For example, one of the respondents to the TLARS (TranScience Longitudinal Aging Research Study) stated that

My insurance specifically excludes TS care, so I'm having trouble with money for medical care. Oregon Health plan excludes mental health, so I can't afford therapy, which I need for surgery. I obtained an inappropriate surgery because I lied to my M.D. about being a TS. I did this because the last time I told a medical professional (University student mental health counsellor) the truth they wanted to institutionalize me. I had serious complications from the surgery, possibly because I was on birth control pills because I could not get testosterone.

\section{Another TLARS respondent reported that:}

Notations re: gender are always disclosed in medical records. Whenever insurance applications are filled out, an authorization for release of all medical records is included. Once the info is disseminated to the insurance carrier, all hope of confidentiality is lost ... providers are not TG friendly.

There is also the inability to access health care coverage where it is not state provided. ${ }^{59}$ Even in the UK where there is a national health service and despite success in the Appeal Court ${ }^{60}$ which held that gender dysphoria was an 'illness' as defined under the National Health Service Acts, the treatment route is difficult because of a shortage of resources and a tendency of health care funders to downgrade the priority of assessment and gender reassignment treatments, ${ }^{61}$ regarding treatments and surgical procedures in particular as being 'cosmetic'.

Implications for malpractice, once a trans person is admitted or attempting to be admitted to long term/nursing home care may also profound. Given the spiralling premiums for professional liability coverage, the market pullouts by liability insurers, and the scarcity of malpractice-insurance coverage facing providers in some US states, ${ }^{62}$ it is reasonable to assume that trans elderly persons may face increasing difficulties in being admitted to long term/nursing home facilities due to fear and outright prejudice on the part of staff in treating such individuals. While there is no

\footnotetext{
${ }^{58}$ American Psychiatric Association, Diagnostic and Statistical Manual of Mental Disorders - DSM IVTR $\left(4^{\text {th }}\right.$ ed, 2000)

${ }^{59}$ Sean Cahill, Ken South and Jean Spade, Outing Age: Report of the NGLTF Task Force on Aging (2000) Washington DC: NGLTF. Available on-line at <http://www.ngltf.org>.

${ }^{60} R v$ North West Lancashire Health Authority; Ex parte A, D, G (2000) WLR 997.

${ }^{61}$ Suffolk Health Authority, Transsexuals and Sex Reassignment Surgery (1994) Available on-line at: <http://www.pfc.org.uk/medical/suffolk.htm>

${ }^{62}$ David M Studdert and David G Stevenson, 'Nursing Home Litigation and Tort Reform: A Case for Exceptionalism' (2004) 44(5) The Gerontologist 588-595
} 
direct published research addressing this topic, there is more than enough anecdotal evidence (Tyra Banks and Robert Eades) of trans individuals being refused appropriate medical attention due to their trans identities. ${ }^{63}$ There is no reason to assume that such $\mathrm{mal} / \mathrm{mistreatment}$ will be any less prevalent in acute care, nursing home and long term care facilities. Coupled with the already well-known stigma of being elderly, the transperson may face increasing difficulty in finding age-appropriate and identity-appropriate treatment and facilities. However, once in such facilities, the transperson may become a natural target for abuse and victimisation.

\section{What Do We Know About Transgender Aging?}

Although many primary health providers such as family doctors may have extensive experience with the trans patient, being old and being trans are only now just becoming common features of those attending for secondary level health provision or seeking care services. Few secondary level providers have experience with working and caring for trans people, and their understanding of care provision needs is often based upon media discourses which infer an 'easy' point of change from one 'sex' to the other, and a point of completion where the body will be indistinguishable from that of others of the acquired gender. ${ }^{64}$ Moreover, this discourse is grounded in a homocentric, two-sex, bi-gender based, Judeo-Christian-Islamic construct that leaves no room for the continuum of gendered identities and bodies that the caretaking profession is soon to see. ${ }^{65}$ Furthermore, hormone therapies in particular have differing efficacies for individuals, and although many trans people may wish to just be an 'ordinary' man or woman, in fact they have adjusted their lives and personal wishes to accept that they may never be, being neither fully 'male' nor fully 'female'. ${ }^{6}$

Many transsexual women are successful in achieving full surgical reassignment of the genitals but some do not; it is still the case that only a very small proportion of transsexual men will obtain phalloplasty surgery. ${ }^{67}$ Other health related conditions, particularly in the older age group, make major surgery contra-indicated. There is clearly going to be a group of older people in which we see women with penises

\footnotetext{
${ }^{63}$ Witten and Eyler, above n 6, 461-469; Lombardi, Wilchins, Priesing and Malouf, above n 16. ${ }^{64}$ Katherine Watson and Stephen Whittle, 'Slicing Through Healthy Bodies: The Media of Body Modification', in Martin King and Katherine Watson (eds), Representing Health: Discourses of Health and Illness in the Media (2004) 104.

${ }^{65}$ Tarynn M Witten, 'Ramifications of the Anthropological Dilemma in Studies of Healthcare Needs involving Sex, Gender, and Sexuality: Healthcare Surveys - A Social Epidemiological Review' (Working Paper 2002-02) TransScience Research Institute (2003).

${ }_{66}$ Adrianne Dana-Tabet in Hartley and Whittle, above n 29.

${ }^{67}$ Lord Chancellor's Department, Government Policy Concerning Transsexual People (2002) Available on-line at: <http://www.constitution/transex/policy.htm>; Tarynn M Witten, 'Life Course Analysis: The Courage To Search For Something More: Middle Adulthood Issues in the Transgender and Intersex Community' (2003b) 8(3-4) J Human Behavior in a Social Environment 189.
} 
and prostates and men with vaginas. We will also see the impacts of long-term hormonal treatment. Currently, there is very little research available on the impact of long term cross sex hormone therapy and none at all on those groups which have undergone such therapy for extensive periods of time. There is knowledge that poor hormone therapies will result in osteoporosis, ${ }^{68}$ have potential implications for oral health and through that cardiovascular and cardiopulmonary health ${ }^{69}$ and that there are increased other risks associated with hormone therapies. ${ }^{70}$ The lack of access to medical facilities raises the spectre of increased needle sharing for hormone use among low-income trans persons. Evidence of the increase in HIV among these populations, particularly among street sex workers is already available. ${ }^{71}$ Moreover, it is already well-documented that one of the fastest growing groups for HIV/AIDS is the over-50 years old population. Implications for the elder-trans population, particularly with the new HIV/AIDS treatments can be profound. ${ }^{72}$ Not only will these individuals be dealing with their age-related medications (of which the average elderly person has 6-9 different prescriptions), but they will also be dealing with their HIV-related and gender-related medications as well.

Surgical procedures have changed considerably over the last 50 years, and whereas there are now trans women who, upon examination, a gynaecologist might just assume had had a full hysterectomy, it is a fairly recent advance. Early male to female genital reconstruction was often surgically harsh and unable to 'last a lifetime'. Genital surgery is complex and still rarely available to most trans men due to cost. Moreover, the limitations of such surgery still cause most trans men to forgo it. Phalloplasty surgery is still basic and leaves the patient very scarred with use of the phallus for sexual activity limited by the lifetime of the prosthetics used, and there is an acknowledgement that the surgery will not resemble an ordinary penis. It could be hypothesised that in fact for many trans people genital surgery, rather than bringing their body closer to the 'norm' in fact makes bodies even more complex and visibly different. Such differences would only serve to further stigmatise and marginalise these individuals. Moreover, it is likely that such differences would serve to increase the likelihood that the "system" would not afford them the rights of a normative elder person using that same system.

\footnotetext{
${ }^{68}$ National Osteoporosis Society Transsexualism And Osteoporosis (2004) <http://www.nos.org.uk/documents/TranssexualismandOsteoporosis>

${ }^{69}$ Tarynn M Witten and A Evan Eyler, 'Hormones and Oral Health: Implications for the Transgender Population' (2004) in preparation.

70 J M Paul and P van Kesteren, Henk Asscheman, Jos Megens and Louis J G Gooren, 'Mortality And Morbidity In Transsexual Subjects Treated With Cross-Sex Hormones' (1997) 47 Clinical Endocrinology 337-342; Tarynn M Witten, 'Transgender Aging: An Emerging Population and an Emerging Need' (2003a) XII(4) Review Sexologies 15-20.

${ }^{71}$ Kristin Clements-Nolle, Rani Marx, Robert Guzman and Mitchell Katz, 'HIV Prevalence, Risk Behaviors, Healthcare Use and Mental Health Status of Transgender Persons: Implications for Public Health Intervention' (2001) 91 American Journal of Public Health 915; Gretchen Kenagy, 'HIV Among Transgendered People' (2002) 14(1) AIDS Care 127; Tooru Nemoto, Don Operario, Joanne Keatley, Lei Han and Toho Soma, 'HIV Risk Behaviors among Male-To-Female Transgender Persons of Color in San Francisco' (2004) 94 American Journal of Public Health 1193.

72 Tarynn M Witten and A Evan Eyler, 'HIV, AIDS and the Elderly Transgendered/ Transsexual: Risk and Invisibility' paper presented at the 1997 Gerontological Society of America, Cincinnati, OH.
} 


\section{Elder Mistreatment and Abuse}

The physiological complexity of older adults is compounded by their enormous psychosocial complexity. ${ }^{73}$ Elder abuse and mistreatment includes physical abuse, sexual abuse, psychological abuse, financial or material exploitation, neglect, selfneglect, and abandonment. In the only national incidence study on elder mistreatment (1996), it was estimated that approximately 550,000 adults aged 60 and over experienced some form of mistreatment. Moreover, this same study estimated that only one in five cases was actually reported to the appropriate adult protection service. ${ }^{74}$ While the study identifies that perpetrators of elder abuse are 'generally individuals on whom older adults depend for care or protection,' it identifies these individuals within the context of the normative ecological structure of the familysocio-economic system. Hence, these results may not apply to members of the LGBT community as a whole or the Trans community in particular. The study further identifies that in the case of self-neglect, 'mistreatment arises from the need for care coupled with no identified care-giver'. ${ }^{75}$ Given the often diminished social support network of trans persons, it is within reason to postulate that there will be significantly increased numbers of elder trans persons who may fall under the category of self-care abuse.

Elder trans persons are also potential victims to multiple forms of elder abuse arising from within the family as well as from external caregivers and other members of socio-economic networks the trans person is trying to use. Children and spouses/former partners of trans persons may feel victimised and angry at having a trans parent or trans partner and feel that their lives have been negatively affected (financially, ${ }^{76}$ emotionally, spiritually, etc.) and may take out these negative feelings on the trans-identified member. Abuse can take many forms from physical abuse to more emotional abuse such as isolation of the transperson from grandchildren or other family members and activities. The isolation can be further exacerbated by the trans person's family's unwillingness to take care of the needs of the elderly trans person, thereby foisting the elder onto the already unwilling social services system. Isolation can also take the form of religious or spiritual isolation. Consider the following case example.

Case 3: US Cynthia is a 38 year old male to female trans woman. Upon returning to her Baptist church after she had had genital surgery, she was told that the only way that she could be a member of

\footnotetext{
${ }^{73}$ Laura Mosqueda, Kerry Burnight, Solomon Liao, and Bryan Kemp. 'Advancing the Field of Elder Mistreatment: A New Model for Integration of Social and Medical Services’ (2004) 44 Gerontologist 703.

${ }^{74}$ Department of Health and Human Services, The National Elder Abuse Incidence Study (1998).

${ }^{75}$ Mosqueda, Burnight, Liao and Kemp, above $\mathrm{n} 73$.

${ }^{76}$ Michael J Tueth, 'Exposing Financial Exploitation of Impaired Elderly Persons' (2000) 8 American Journal of Geriatric Psychiatry 104.
} 
the parish was to realise that she had sinned by altering her body. Moreover, the church insisted that she promise to remain celibate.

In Cynthia's case, she was able to find a more accepting church. Others are not so lucky. Many do not find any spiritual respite and must resort to private solutions. And, in doing this, they lose the former social support networks they had developed and upon which they had come to depend. The importance of spirituality/religiosity has been repeatedly demonstrated in the Gerontological and Geriatric literature and is beyond the scope of this article to discuss. Results from the TLARS research show that over $95 \%$ of the respondents indicated that they professed some form of religiosity or spirituality.

Elder abuse can take on complex dynamics.

Case 4: US Frank's 90 year-old father Bob lives alone in his own home and has COPD. He requires Frank's daily visitation. Frank is a 68 year-old transman who has lived, with full surgical realignment, in his target identity for over 30 years. Bob's unresolved anger at Frank's transition leads him to abusive behaviours against Frank. Frank finds he is increasingly unable to control his own anger and has had numerous shouting matches with his father; recently having to restrain himself from hitting Bob.

Here we see an example of elder-upon-elder abuse. Abuse may also be perpetrated upon trans elders by care providers, either through absence of policy (we can't take care of trans persons because we don't have the facilities), through direct policy (trans is explicitly excluded from our services), through ignorance of the special needs of trans (I would take care of trans persons, but I don't know what to do so Case 2 UK), or through direct intent (We don't want their kind here).

Given the systems' current inability to handle elder mistreatment and abuse, there is no reason to believe that the system would be elder trans friendly. Moreover, one can readily postulate that it is likely to be extremely unfriendly to elder trans abuse, particularly since trans violence is not covered under Hate Crimes law. Furthermore, the lack of geriatricians, psychologists, gero-psychiatrists, geriatric social workers, and geriatric nurses who are trained to deal with elder abuse and mistreatment ${ }^{77}$ reinforces the fact that there are even fewer who will be able to handle the issues that might arise around abuse and mistreatment of an elder trans person.

Disabled elders who are also trans identified may well suffer multiple forms of abuse due to their multiple marginalising states of being disabled, elder, and trans identified. While there are no estimates for the number of disabled trans persons, the field research work of Witten and Eyler has demonstrated that there are elder trans persons who are deaf/mute as well as persons who are wheelchair-bound.

\footnotetext{
${ }^{77}$ Mosqueda, Burnight, Liao, and Kemp, above n 73.
} 
There is no reason to believe that the trans population would be any different, in its disability rates, from the general population.

\section{$X \quad$ Legal Rights to Health and Social Care for Transgender Persons as They Age}

Disability discrimination might well be considered a route by which trans people could be afforded protection. Because gender dysphoria is contained within the psychiatric diagnostic manual, DSM-IV TR, ${ }^{78}$ there is an intrinsic presumption that gender dysphoria is a mental health disorder which is long term, and possibly even permanent. In Hong Kong, the Equal Opportunities Commission has recently used the Disability Discrimination Ordinance to instruct the Hong Kong Examinations and Assessment Authority to issue a new examination certificate to a transsexual woman, bearing only her new name and gender. ${ }^{79}$ This might be effective in some states, such as the UK, but in the USA the Americans with Disabilities Act of 1990 explicitly excludes transsexual people stating that transsexualism and gender identity disorders are not, without a physical causation, considered disabilities. ${ }^{80}$

The question of using disability discrimination laws has proven problematic as trans people have argued against the medicalisation of their identities, wishing to have the condition removed from the psychiatric remit. Such an approach presents a significant problem in that it is very difficult to consider where else such a diagnosis might belong and yet still enable some claim to national or local insurance health schemes. Further the disability tag in itself carries some stigmatisation, although it appears that it may be declining. It is counter-argued that trans people by refusing the 'disabled' label are presuming that the ownership of the label is in some way shameful and it is indicative of their own prejudices. Either way, if the label were to be claimed, it may well be that the protection of disability ordinances could be claimed in the areas of goods, services and housing. The various statutes have not been used to challenge a failure of equal access and provision of goods and services through the courts, though several cases have been settled out of court. There have been some limited successes in using state laws in employment issues such as the Florida case of Smith v City of Jacksonville, ${ }^{81}$ but this is was successful on the basis of sex stereotyping rather than the disability question.

Article 25, paragraph 1, of the United Nations' Universal Declaration of Human Rights establishes that:

\footnotetext{
${ }^{78}$ American Psychiatric Association, Diagnostic and Statistical Manual of Mental Disorders - DSM IVTR (4th ed, 2000).

${ }^{79}$ Ravina Shamdasani, 'Victory for Woman in Gender Bias Dispute', The South China Morning Post, 4 October 2003, C4.

${ }^{80}$ Americans With Disabilities Act of 1990, 29 USC $\S \S 12101$ et seq. (1990) s. 511.

${ }^{81}$ Smith v City of Jacksonville Correctional Institution, WL 833882 (Fla. Div. Admin. Hrgs. 1991).
} 
Everyone has the right to a standard of living adequate for the health and well-being of himself and of his family, including food, clothing, housing, and medical care and necessary social services, and the right to security in the event of unemployment, sickness, disability, widowhood, old age or other lack of livelihood in circumstances beyond his control.

There is an increasing recognition that an aging population have needs that should be ensured. Human rights instruments in recent years have started to acknowledge the principle that the elderly should have a right to protection, participation and image but, as is the case with all rights, ensuring rights depends not just on legislative will and policies but on the ability to enforce those rights. Ensuring implementation often depends on the finances and methods to pursue the state for its failure to ensure rights. The elderly are rarely in a position to enforce rights, and invariably depend upon good will or good practice.

There are several legislative systems that afford protection on age grounds, such as the federal Age Discrimination in Employment Act ${ }^{82}$ in the USA, which prohibits employers from discriminating against employees and applicants who are 40 years of age or older on the basis of their age. But these presume that the person has the means to pursue a claim. They also presume that discrimination is 'single facetted' whereas in fact it is increasingly recognised that people face multiple discriminations. Ensuring that individuals do not have their claims rejected because one part of the discrimination they face is not unlawful demands a new approach to discrimination law.

In the last 10 years the 'grey' movement has become more visible, claiming the right of older people to financial security, health care and life long education. But whether it will be a vehicle for enforcing the rights of the most vulnerable of the older age group is a different question. Inevitably it will be a movement of the most able and articulate with the best (although limited) financial resources concentrating on the issue of independent living. There has been little discussion as yet as to conception of the movement as an altruistic pressure group, perhaps primarily because there is an urgency of personal need for many of its members. There simply is not time to take on board the needs of the even more vulnerable.

The principle that discrimination based on gender identity should be illegal, as has been seen, has only been upheld in very limited areas of life. Employment and vocational training may be covered, but it is only in very few states that the provision of goods and services is also guaranteed. The move to discrimination law which covers all areas of life and which addresses arbitrary and unfound discrimination which negatively impacts on the lives of people is desperately needed. The UK is currently considering the creation of a new 'Equalities' body, the Commission for Equalities and Human Rights (CEHR), which would encapsulate all the duties of prior Equality bodies- the Commission for Racial Equality, the Equal

\footnotetext{
${ }^{82}$ Age Discrimination In Employment Act of 1967, 29 USC §§ 621-34 (1994).
} 
Opportunities Commission (sex equality) and the Disability Rights Commission. The overall remit is larger in that the CEHR's duties would include supporting not just equality issues but also human rights claims based on the European Convention on Human Rights and the UK's Human Rights Act 1999. If we were to 'blue sky' the role of this Commission, one would hope that gender identity would be clearly within its sphere of activity even if not a main strand of activity. It could well prove a very useful model for other states.

\section{Implications for legal Practice}

Legal practice in this area has to be daring and willing to take risks. Worldwide there is little clear legislation and few case law precedents. Human rights and constitutional claims have been made, and recent social changes arising from transgender campaigning, education and advocacy are now producing some successes. In the European Community employment protection, privacy and the right to marriage is now technically available to all transsexual people if not all trans people. In the USA employment protection cases are gradually being successful and in Ohio, the Appeals Court has held that Title VII of the Civil Rights Act there which prohibits employment discrimination based on race, colour, religion, sex and national origin provides protection to trans people in employment ${ }^{83}$ and that sex stereotyping is no longer lawful. Whether this principle could be transferred to the provision of goods and services at a federal level however is another matter! Marriage is a much more complex question, with recent cases at state level undermining the right to marriage $^{84}$ in the USA.

In Australia although most states now afford some protection to trans people, the extent of the protection, other than in the area of marriage and social security benefits, ${ }^{85}$ has not been tested. Obviously, the importance of marriage or its legal equivalent is important. Marriage affords long term stability, not only emotionally and financially, but also provides inheritance and property transfer rights and protection in the case of death. ${ }^{86}$ All of these facets are important for successful aging in the "normative" population and have no less import in the trans elderly population.

\footnotetext{
${ }^{83}$ Smith $v$ City of Salem, 378 F.3d 566 (6th Cir. 2004).

${ }^{84}$ Littleton v Prange, 9 S.W.3d 223 (Tx Ct App, 4th Dist, 1999), Kantaras v Kantaras No. 2D03-1377

(Fla Ct App, 2nd Dist, 2004).

${ }^{85}$ Department of Social Security $v$ SRA (1993) 118 ALR 467.

${ }^{86}$ Stephen Whittle, 'Sex: Has it Any Place in Modern Marriage' in Robert Wintemute and Max Andenaes (eds), Legal Recognition of Same Sex Partnerships (2001) 693.
} 


\section{Conclusions}

None of the case law or legislation truly acknowledges the ongoing challenges of the vast diversity within the trans population, whether that diversity arises out of the complexity of personal identity, or the diversity of body modifications that have been undertaken. The transgender community has itself embraced this diversity in the sense that it is now made up of a range of people with differing versions of sexed and gendered bodies. To ensure respect, dignity and to adjust support to meet the individual need, it is imperative that the mythology of the trans body be erased and replaced with reality. It is the role of the law to ensure fairness and equality for all. For the older trans person, who has weathered the challenges of a difficult life and suffered the social stigma, poverty and health impact of achieving as full a life as possible, it is important that they are not re-stigmatised when they reach their later years. This demands a commitment from social and health care providers to respect the diversity of their bodies, and to enable the use of the law wherever it is needed to enforce that respect. However, that will not be possible until discrimination laws acknowledge the multi-faceted nature of discrimination and the need to acknowledge the whole person when resolving these issues. 